\title{
Desempenho dos municípios do Rio Grande do Sul na execução dos recursos do PNAE com a agricultura familiar
}

\author{
The performance of municipalities of Rio Grande do Sul in the \\ implementation of the resources of the PNAE with family agriculture
}

\author{
Alexandre $\operatorname{Troian}^{1}{ }^{(1)}$, Alessandra Troian ${ }^{2}$ (B), Sibele Vasconcelos de Oliveira ${ }^{3}$ (D), \\ Josiane Castro Pereira ${ }^{4}$ (D)
}

${ }^{1}$ Faculdade de Agronomia Eliseu Maciel, Universidade Federal de Pelotas (UFPel), Pelotas, (RS), Brasil. E-mail: xtroian@gmail.com

${ }^{2}$ Programa de Pós-graduação em Administração, Universidade Federal do Pampa (UNIPAMPA), Santana do Livramento (RS), Brasil. E-mail: alessandratroian@unipampa.edu.br

${ }^{3}$ Programa de Pós-graduação em Economia e Desenvolvimento, Departamento de Economia e Relações Internacionais, Universidade Federal de Santa Maria (UFSM), Santa Maria (RS), Brasil. E-mail: Sibele.oliveira@ufsm.br

4Programa de Pós-graduação em Administração, Universidade Federal do Pampa (UNIPAMPA), Santana do Livramento (RS), Brasil. E-mail: josiane_122@hotmail.com

\begin{abstract}
Como citar: Troian, A., Troian, A., Oliveira, S. V., \& Pereira, J. C. (2020). Desempenho dos municípios do Rio Grande do Sul na execução dos recursos do PNAE com a agricultura familiar. Revista de Economia e Sociologia Rural, 58(3), e204558. https://doi.org/10.1590/1806-9479.2020.204558
\end{abstract}

Resumo: A agricultura familiar brasileira é responsável por gerar emprego e renda no campo, além de fornecer alimentos à população. Deste modo, é estratégico para o Estado conceber mecanismos que possam contribuir para amenizar vulnerabilidades socioeconômicas enfrentadas por este segmento. Dentre as políticas públicas com este ofício, destaca-se a experiência na constituição dos mercados institucionais, como é o caso do Programa Nacional de Alimentação Escolar (PNAE). Destarte, a presente pesquisa visa analisar o desempenho dos municípios do Rio Grande do Sul (BR) no tocante aos investimentos realizados na aquisição de produtos alimentares da agricultura familiar destinados à alimentação escolar durante os anos de 2011 a 2016. Para tanto, foram realizadas pesquisas documental, bibliográfica e analisados dados secundários disponibilizados no Sistema de Gestão de Contas do portal Fundo Nacional da Educação. Constatou-se que o Rio Grande do Sul investiu 24,9\% do recurso financeiro disponibilizado para o PNAE em alimentos oriundos da agricultura familiar, sendo que $67 \%$ dos municípios sul-rio-grandenses cumpriram a meta estabelecida na Lei n. 11.947/2009. Ainda, observa-se o crescimento da quantidade de municípios que aderiram ao programa e do volume de recursos negociados com agricultura familiar ao longo do período analisado.

Palavras-chave: agricultura familiar, mercados institucionais, desenvolvimento rural.

\begin{abstract}
The family farming in Brazil is responsible for generating employment and income in the countryside, as well as providing food to the population. In this sense, it is strategic for the State to devise mechanisms that may contribute to mitigating the socioeconomic vulnerabilities faced by this segment. Among public policies with this office, it is highlighted the Brazilian experience in the constitution of institutional markets, such as the National School Feeding Program (PNAE). The present work aims to analyze the performance of the municipalities of Rio Grande do Sul (BR), in the period from 2011 to 2016, in relation to the investments made in the acquisition of food products from family agriculture for school feeding. For this propose, it was made a documentary and bibliographic research and were analyzed secondary data available in the Account Management System of the National Education Fund. It was verified that the Rio Grande do Sul invested $24.9 \%$ of the resource available for PNAE in food from family agriculture, and $67 \%$ of the municipalities of Rio Grande do Sul compiled the goal established in Law 11.947/2009. The results illustrate an increasing trend in the number of municipalities that joined the program and show an increase in the volume of resources negotiated with family farms over the period analyzed.
\end{abstract}

Keywords: family farming, institutional markets, rural development. 


\section{INTRODUÇÃO}

A agricultura familiar é um segmento social que combina diferentes fatores produtivos em uma dinâmica muito particular. Com protagonismo da família na gestão e no trabalho, é uma categoria heterogênea e varia em diferentes gradientes de renda, área do estabelecimento, condições de acesso à terra, grau de especialização ou diversificação da produção.

No Brasil, os dados dos censos agropecuários de 1996 e 2006, realizados pelo Instituto Brasileiro de Geografia e Estatística (IBGE), revelam que dos cerca de 5,1 milhões de estabelecimentos agropecuários brasileiros, $84,3 \%$ são do tipo familiares, sendo que ocupam menos de $25 \%$ da área nacional e produzem quase duas vezes o valor bruto área/ano da agricultura considerada não familiar. Além das vantagens sobre a produtividade econômica da área, a produção agrícola familiar é responsável por gerar ocupação para 12.323.110 pessoas (Instituto Brasileiro de Geografia e Estatística, 2006).

Embora o Brasil necessite de um novo censo para atualizar as informações sobre o perfil da agricultura brasileira, reconhecidamente a agricultura familiar tem demonstrado importância ao estimular e desenvolver a economia de comunidades rurais. Por isso, o atendimento a suas demandas é fundamental, especialmente quando da elaboração de programas de governo e políticas públicas.

Sobretudo, ressalta-se que o compromisso do Estado com a agricultura familiar vai além da promoção de políticas que disponibilizam crédito e apoio técnico. O ente estatal passa a atuar como um agente regulador indispensável para estimular a agricultura familiar a produzir alimentos em quantidade e qualidade através da construção social de mercados nos sistemas agroalimentares. Neste sentido, conforme corrobora Veiga $(1991,1992)$, quando o alimento é ofertado a preços baixos, há transferência de renda da agricultura para outros setores da sociedade. Pode significar, por conseguinte, a diminuição nos custos de reprodução da força de trabalho e aumento do poder aquisitivo dos assalariados, Ihes permitindo gastar mais com bens duráveis.

A atuação do governo brasileiro como mediador nos mercados de gêneros alimentícios tem se consolidado nos últimos anos, especialmente após os anos 1990. Os chamados mercados institucionais, desempenhados através do Programa Nacional de Alimentação (PAA) e do Programa Nacional de Alimentação Escolar (PNAE), são mecanismos de comercialização que favorecem a aquisição direta de produtos alimentícios de agricultores familiares, fortalecendo a agricultura familiar e as economias regionais, amenizando o problema social da fome e estimulando hábitos alimentares saudáveis (Brasil, 2016).

Apesar da importância da agricultura familiar, a categorial social enfrenta dificuldades, inclusive na comercialização dos seus produtos. Por isso, políticas públicas como o PNAE contribuem para a transformação social e econômica (Rozendo et al., 2013). Diante da importância das políticas públicas de apoio à agricultura de base familiar e de sua contribuição para o desenvolvimento da sociedade, o presente estudo tem como objetivo central analisar o desempenho dos investimentos realizados na aquisição de produtos alimentares da agricultura familiar destinados à alimentação escolar, via PNAE, nos municípios do Rio Grande do Sul (BR) entre o período de 2011 e 2016.

Em síntese, buscou-se: i) averiguar se os percentuais médios de investimento de recursos na compra de alimentos da agricultura familiar aumentou no período analisado, indicando, portanto, avanços no arranjo do programa; ii) analisar o desempenho dos municípios entre as sete mesorregiões (conforme classificação do IBGE) do Rio Grande do Sul, para averiguar se há uniformidade na execução no Estado; iii) verificar se há diferença entre a otimização dos recursos com a agricultura familiar nos municípios mais e menos populosos.

O artigo está organizado em quatro seções, além deste tópico introdutório. A seguir, retrata-se a relação da agricultura familiar com os mercados institucionais. Na sequência, são apresentados os procedimentos metodológicos empregados para a realização da pesquisa. Posteriormente, realiza-se explanação acerca da performance da execução financeira dos recursos destinados à compra de alimentação escolar no Rio Grande do Sul com a agricultura familiar. Por fim, apresentam-se as principais considerações desta análise e os referenciais bibliográficos consultados no transcorrer da pesquisa. 


\section{AGRICULTURA FAMILIAR E MERCADOS INSTITUCIONAIS NO BRASIL}

Apresenta-se a seguir um panorama geral sobre a agricultura familiar no Brasil, caracterizando-a e expondo suas principais especificidades. Ademais, discute-se sobre a relação da agricultura com os mercados, voltando-se para a inserção dos agricultores familiares nos mercados institucionais e, em especial, no Programa Nacional de Alimentação Escolar.

\subsection{Agricultura familiar: das características ao acesso aos mercados}

O modelo de produção agrícola instituído no pós-guerra é pautado na utilização de insumos químicos, uso intensivo da mecanização e melhoramento genético. Este modelo tem possibilitado ao Brasil conquistar resultados de crescimento na produção em larga escala nas últimas décadas. Todavia, tem apresentado também robustos impactos sobre o meio ambiente, além da concentração, centralização e controle do capital sobre a agricultura (Sabourin et al., 2009).

De acordo com Wanderley (2003), a recente dinâmica de desenvolvimento da agricultura foi condicionada pela modernização das atividades produtivas e pela integração aos mercados globais. Contudo, manteve-se a pluralidade e heterogeneidade das formas sociais de produção, de modo que a agricultura familiar ocupa espaços culturais e econômicos importantes nas mais diversas regiões do país.

Aquino et al. (2018) argumentam que é possível perceber expressivas diferenciações entre integrantes deste mesmo estrato, assinaladas por diferentes sistemas de produção, recursos fundiários, formas de obtenção de renda, entre outros. A despeito das particularidades apresentadas, pode-se denominar agricultura familiar o modo de produção agrícola em que a exploração produtiva, o consumo e a gestão da propriedade são exercidos singularmente pela família. Assim, é considerada uma forma social de produção, reconhecida por suas contribuições materiais e imateriais à sociedade (Delgado \& Bergamasco, 2017).

Ademais, segundo a legislação brasileira, o agricultor familiar é aquele que pratica suas atividades no meio rural, atendendo simultaneamente aos seguintes requisitos: não deter área superior do que 4 módulos fiscais; utilizar predominantemente mão de obra da própria família nas atividades econômicas do estabelecimento; obter um percentual mínimo da renda originada em atividades econômicas do estabelecimento; ademais de gerenciar com a família o seu empreendimento (Brasil, 2006, art. 3).

Para além de uma forma de organização da produção, a agricultura familiar é um modo de vida que vem, ao longo dos anos, resistindo e se adaptando aos padrões de desenvolvimento da agricultura moderna. Sob a lógica de reprodução da agricultura familiar, parte da produção agrícola tanto pode ser comercializada como consumida na unidade doméstica. Ainda, os mercados supõem laços pessoais entre os agentes, de forma que as operações mercantis se desenvolvem num ambiente com esfera não estritamente econômica. Decorre destas particularidades que os agricultores familiares instituem inserções parciais aos mercados (Abramovay, 1992) e mantém uma lógica de consumo e comercialização que se constitui em uma esfera relativamente autônoma.

Conforme argumenta Ploeg (2008), a capacidade da agricultura familiar em se manter economicamente viável depende da forma como os atores organizam seu processo produtivo e planejam sua forma de inserção nos mercados. De fato, a capacidade de exploração agrícola familiar constitui múltiplas realidades e é expressa através de diferentes graus de tecnificação e integração aos mercados, conforme dados estatísticos expressos por meio da Tabela 1.

Do universo de mais 4,5 milhões de estabelecimentos agropecuários familiares brasileiros, $48 \%$ são integrados ou muito integrados aos mercados. Nestes dois grupos, participam com maior representatividade nos mercados os agricultores muito especializados $(46,6 \%)$ e especializados (26,3\%). Por outro lado, $18 \%$ de todos os estabelecimentos brasileiros são diversificados e pouco integrados (Instituto Brasileiro de Geografia e Estatística, 2006). 
Tabela 1. Agricultores familiares integrados aos mercados no Brasil, segundo grau de especialização das atividades produtivas

\begin{tabular}{cccccc}
$\begin{array}{c}\text { Grau de } \\
\text { especialização dos } \\
\text { agricultores } \\
\text { familiares }\end{array}$ & $\begin{array}{c}\text { Muito } \\
\text { integrado }\end{array}$ & Integrado & $\begin{array}{c}\text { Pouco } \\
\text { integrado }\end{array}$ & $\begin{array}{c}\text { Não } \\
\text { identificado }\end{array}$ & Total \\
\cline { 2 - 6 } Muito especializado & 478.767 & 96.773 & 347.006 & - & 922.546 \\
Especializado & 498.617 & 520.971 & 599.526 & - & 1.619 .114 \\
Muito diversificado & 2.990 & 33.737 & 140.890 & - & 177.617 \\
Diversificado & 133.103 & 421.078 & 820.828 & - & 1.375 .009 \\
Não identificado & - & - & - & 457.569 & 457.569 \\
Total & 1.113 .477 & 1.072 .559 & 1.908 .250 & 457.569 & 4.551 .855 \\
\hline
\end{tabular}

Fonte: Instituto Brasileiro de Geografia e Estatística (2006).

Vale mencionar que a classificação empregada pelo Instituto Brasileiro de Geografia e Estatística considera o valor total da receita com atividade agropecuária e o valor total da produção agropecuária em estabelecimentos de agricultura familiar. Já o nível de especialização foi obtido através do quociente entre o valor da produção do produto principal do estabelecimento e o valor total da produção (Instituto Brasileiro de Geografia e Estatística, 2006).

Polanyi (1980) argumenta que os mercados são considerados locais de encontro (não necessariamente físico) entre sujeitos para a permuta de objetos. Uma diversidade de fatores de natureza humana e social, como a tradição, a simbologia, os valores, crenças e necessidades, estão contidas neste processo de interação social. Neste sentido, ao se analisar o processo de transformação e de adaptação da agricultura familiar através da mercantilização, faz-se necessário conhecer que mercados são acessados pelos agricultores familiares, uma vez que eles constituem uma das formas de interação da agricultura familiar com a sociedade.

Ao ingressar no mercado e criar condições de reprodução socioeconômica para seus integrantes, a agricultura familiar pode fortalecer o tecido social e produtivo do desenvolvimento local. Apesar de enfrentar entraves e desafios para escoar a sua produção, os agricultores familiares encontram no acesso aos mercados a estratégia fundamental de comercializar seus produtos. Ademais, a conexão existente entre quem produz e quem compra promove a confiabilidade do produto, a qual se torna um diferencial na comercialização da agricultura familiar, promovendo a preservação da cultura regional (Schneider \& Escher, 2011).

Neste sentido, o acesso aos mercados pela agricultura familiar oportuniza a realização de benefícios tanto para os agricultores, que se favorecem com a comercialização da sua produção, quanto para os indivíduos consumidores, que têm maior diversidade e oferta de alimentos de qualidade. Sobretudo, segundo Sabourin (2011), não existe apenas "um modelo de mercado" focado no crescimento econômico e atendimento de necessidades privadas. Para o autor, existem alternativas de mercados que extrapolam a simples troca de bens e de interesses individuais e podem incluir relações sociais e valores comunitários éticos ou espirituais.

Sob esta perspectiva, os mercados são percebidos como socialmente construídos e refletem as escolhas individuais (Bromley, 1997). Segundo Wilkinson (2008), existem pelo menos quatro formas tradicionais de acesso aos mercados na agricultura familiar: o acesso direto (mercado local/informal), a intermediação via atravessador, a integração com a agroindústria e mercados constituídos via compras governamentais.

Ainda, Schneider (2016) propõe quatro tipologias para caracterizar os mercados acessados pela agricultura familiar, a saber, os mercados de proximidade, os mercados locais 
e territoriais, os mercados convencionais e os mercados públicos e institucionais. Para tanto, o autor conceitua os mercados como: a) uma delimitação espacial (locus), onde são realizadas as trocas materiais de bens; b) um ordenador da sociedade e da economia; c) uma construção social, resultante do contato e interações entre distintos agentes, que interagem por razões econômicas, sociais ou culturais.

O Quadro 1 apresenta uma síntese das características dos mercados acessados por agricultores familiares a partir das quatro categorias definidas por Schneider (2016).

Quadro 1. Modalidades de mercados acessados pela agricultura familiar

\begin{tabular}{|c|c|c|}
\hline Categoria & Especificidades dos mercados & Exemplificações \\
\hline Mercado de proximidade & $\begin{array}{c}\text { Prevalece a atuação com base em } \\
\text { trocas diretas, onde são valoradas } \\
\text { as relações de trocas interpessoais } \\
\text { e a qualidade dos bens } \\
\text { transacionados. }\end{array}$ & $\begin{array}{l}\text { - Iniciativas em economia } \\
\text { solidária; } \\
\text { - Venda direta do produtor } \\
\text { ao consumidor. }\end{array}$ \\
\hline Mercados locais e territoriais & $\begin{array}{c}\text { Trocas econômicas monetizadas e } \\
\text { orientadas pela oferta e demanda. } \\
\text { Caracterizada por uma economia } \\
\text { mercantil simples. }\end{array}$ & $\begin{array}{l}\text { - Feiras locais; } \\
\text { - Espaços públicos de } \\
\text { vendas; } \\
\text { - Leilões. }\end{array}$ \\
\hline Mercados convencionais & $\begin{array}{l}\text { Prevalecem as trocas econômicas } \\
\text { orientadas pela oferta e demanda e } \\
\text { que são comandadas por } \\
\text { poderosos agentes privados. } \\
\text { Caracterizada por uma economia } \\
\text { de mercado definida por Polanyi. }\end{array}$ & $\begin{array}{l}\text { - Esferas de distribuição } \\
\text { nacional; } \\
\text { - Supermercados. }\end{array}$ \\
\hline $\begin{array}{l}\text { Mercados públicos e } \\
\text { institucionais }\end{array}$ & $\begin{array}{l}\text { Espaços de troca em que o Estado, } \\
\text { organismos públicos ou entidades } \\
\text { não governamentais são os } \\
\text { principais agentes. }\end{array}$ & $\begin{array}{l}\text { - Programa Mundial de } \\
\text { Alimentos da ONU; } \\
\text { - Estoques do governo; } \\
\text { - PAA; } \\
\text { - PNAE. }\end{array}$ \\
\hline
\end{tabular}

Fonte: Schneider (2016, p. 122-125).

Além da constituição de espaços de trocas econômicas, Becker \& Sacco dos Anjos (2015) destacam que os mercados institucionais da agricultura familiar visam também atuar em questões como a inserção socioprodutiva, segurança e educação alimentar, geração de trabalho e renda, incentivo à agroecologia, entre outras dimensões. Logo, tendo em vista a emergência dos mercados públicos e institucionais nos últimos anos, especialmente no Brasil, discorre-se sobre suas particularidades na próxima seção.

\subsection{Mercados institucionais no Brasil: o caso do PNAE}

As políticas de apoio econômico e produtivo direcionadas para a agricultura familiar no Brasil foram fortalecidas desde a promulgação da Lei $n^{\circ} 11.326 / 2006$. Dentre as iniciativas mais importantes, podem ser citadas a expansão das linhas de crédito rural via Programa Nacional de Fortalecimento da Agricultura Familiar (PRONAF), a nova Assistência Técnica e Extensão Rural (ATER), Seguro Agrícola Familiar (SEAF), o Programa de Aquisição de Alimentos (PAA) e a reestruturação do Programa Nacional de Alimentação Escolar (PNAE) (Gazolla \& Schneider, 2013). Estes instrumentos de política pública, ao disponibilizarem crédito, assessoria técnica e ao possibilitarem a criação de canais de comercialização para os produtos agrícolas, visam proteger as populações rurais e criar condições para sua reprodução socioeconômica.

Sobretudo, é possível perceber que o sistema de comercialização de produtos agrícolas fomentado pelo estado brasileiro apresenta múltiplas finalidades, tanto sob a perspectiva do consumo quanto sob o viés produtivo. Neste modelo de mercado, as trocas econômicas orientadas pelas relações clássicas de mercado (oferta-procura e maximização dos lucros) são 
substituídas por uma espécie de "cooperação interinstitucional", em que fornecedores, compradores e consumidores se articulam, tendo como base o diálogo e o planejamento prévios (Maciel, 2008). Mesmo que as referências de fixação de preços, quantitativos de compra e qualidade requerida sejam estabelecidas por normas e parâmetros específicos, não necessariamente são eliminadas as relações de negociação e de apoio mútuo.

Assim sendo, infere-se que a experiência brasileira na construção de mercados institucionais tem galgado relativos resultados positivos, especialmente quando são observados o alcance e a abrangência do Programa de Aquisição de Alimentos da Agricultura Familiar (Becker \& Sacco dos Anjos, 2015; Ferigollo et al., 2017; Troian \& Caldas, 2018). Vale ressaltar que o PNAE foi criado sob a Lei 10.696 no ano de 2003 e objetiva intermediar a aquisição de produtos alimentícios de agricultores familiares para a formação de estoques ou para doação às pessoas que se encontram em situação de insegurança alimentar/nutricional (Brasil, 2003, art. 19).

Os produtos destinados para doação são oferecidos para entidades assistenciais, restaurantes populares, cozinhas comunitárias e para cestas de alimentos distribuídas pelo governo federal. Ainda, parte dos alimentos é adquirida pelas organizações da agricultura familiar para formação de estoques próprios. A compra é realizada sem licitação, via chamada pública. Cada agricultor pode acessar até um limite anual e os preços não devem ultrapassar o valor dos preços praticados nos mercados locais (Brasil, 2017a).

Conforme o Decreto $n^{\circ}$ 8.293/2014, a execução do PAA pode ser feita por meio de seis modalidades: i) Compra com Doação Simultânea (individualmente até $\mathrm{R} \$ 6,5 \mathrm{mil} / \mathrm{ano}$, ou até $\mathrm{R} \$ 8 \mathrm{mil} / \mathrm{ano}$, caso as operações sejam realizadas por meio de cooperativas ou associações); ii) Compra Direta ( $\mathrm{R} \$ 8 \mathrm{mil} / \mathrm{ano}) ;$ iii) Apoio à Formação de Estoques ( $\mathrm{R} \$ 8 \mathrm{mil} / \mathrm{ano})$; iv) Incentivo à Produção e ao Consumo de Leite $(\mathrm{R} \$ 8 \mathrm{mil} / \mathrm{ano})$; v) Compra Institucional ( $\mathrm{R} \$ 20 \mathrm{mil} / \mathrm{ano}$ por órgão executor); e vi) Aquisição de Sementes ( $R \$ 16 \mathrm{mil} / \mathrm{ano}$ ).

Sabourin et al. (2009) afirmam que o PAA tem sido responsável pela promoção da produção de alimentos advindos dos agricultores familiares e por criar condições para que os camponeses possam ampliar sua participação nos mercados agroindustriais. Ademais, tem permitido que o sistema de abastecimento dos órgãos públicos seja mais eficiente, conte com alimentos seguros e nutricionalmente saudáveis.

A experiência positiva do Programa de Aquisição de Alimentos fomentou a revisão em outros programas governamentais, especialmente o da alimentação escolar. O Programa Nacional de Alimentação Escolar (PNAE), embora existente desde a década de 1950, ganhou novo formato e passou a ser discutido como um instrumento para a segurança alimentar e também para o desenvolvimento da agricultura, através das compras públicas realizadas junto aos agricultores familiares (Fundo Nacional de Desenvolvimento da Educação, 2014).

Com a instituição da Lei n. 11.947 de 16 de junho de 2009, o PNAE, que tinha como prioridade mitigar a desnutrição dos alunos, passa a estabelecer critérios sociais e nutricionais para a compra de alimentos. Deste modo, a alteração na política da alimentação escolar foi um passo em prol do fortalecimento da agricultura familiar brasileira.

A Lei $n^{\circ} 11.947 / 2009$ introduziu um relevante instrumento de reconhecimento do papel socioeconômico da agricultura familiar na produção de alimentos no Brasil. De acordo com a normativa, ficou determinado que, no mínimo, $30 \%$ do valor destinado à alimentação escolar brasileira deve ser investido na compra direta de produtos da agricultura familiar.

Art. 14. Do total dos recursos financeiros repassados pelo FNDE, no âmbito do PNAE, no mínimo 30\% (trinta por cento) deverão ser utilizados na aquisição de gêneros alimentícios diretamente da agricultura familiar e do empreendedor familiar rural ou de suas organizações, priorizando-se os assentamentos da reforma agrária, as comunidades tradicionais indígenas e comunidades quilombolas (Brasil, 2009, art. 24).

Tendo em vista o exposto, o PNAE trata-se de uma política pública desenvolvida para incentivar a agricultura familiar, promover a inclusão social no campo e garantir a oferta de alimentos de qualidade nas escolas brasileiras. Além de instituir uma nova categoria mercadológica, a da alimentação escolar, o programa colabora com o desenvolvimento da agricultura familiar local e incentiva a produção de alimentos de forma sustentável. Cabe 
destacar que, para a compra de produtos orgânicos ou agroecológicos, os preços podem ser acrescidos em até 30\% em relação aos preços estabelecidos para produtos convencionais.

São beneficiários diretos do PNAE os alunos da educação básica brasileira, a incluir os alunos da educação infantil, ensino fundamental, médio e educação de jovens e adultos matriculados em escolas públicas e filantrópicas, além de entidades comunitárias conveniadas com o poder público. A qualidade na alimentação deve desencadear a manutenção e apropriação de hábitos alimentares saudáveis deste público (Brasil, 2009).

Para Triches \& Schneider (2010), a atual configuração do Programa Nacional de Alimentação Escolar é decorrente de um modelo de desenvolvimento que promove justiça social, conservação ambiental e saúde pública, ou seja, que visa mais que crescimento econômico. A história do programa evidencia a substituição de um modelo que incentivou o consumo e a produção de alimentos processados pela indústria, por outro que pretende incentivar a produção e o consumo de alimentos da agricultura familiar menos processado. Tal estratégia pauta-se na relevância desse segmento produtivo para a Segurança Alimentar e Nutricional da população brasileira (Triches \& Schneider, 2010).

Assim sendo, as alterações realizadas no programa vão ao encontro dos preceitos da Segurança Alimentar e Nutricional e do Direito Humano à Alimentação adequada e confirmam importantes transformações na forma de desenvolvimento do país. Por conseguinte, alinham-se aos objetivos previstos pelo II Plano Nacional de Segurança Alimentar e Nutricional (PLANSAN 2016-2019), que visam atingir um conjunto de 121 metas, pautadas no combate à insegurança alimentar e nutricional, inclusão produtiva rural, no estímulo a hábitos alimentares saudáveis, promoção da produção de alimentos sustentáveis e o fortalecimento de sistemas de produção de base agroecológica (Brasil, 2017b).

Por conseguinte, o Programa Nacional de Alimentação Escolar reconhece e valoriza a agricultura familiar, constituindo-se em um mercado institucional capaz de promover o desenvolvimento local. A despeito dos diversos benefícios econômicos, sociais e nutricionais provenientes da aquisição dos alimentos produzidos da agricultura familiar, sabe-se que os municípios brasileiros ainda enfrentam dificuldades em cumprir a legislação (Ferigollo et al., 2017). A partir do estudo realizado no Rio Grande do Sul, Rockett et al. (2019) destacam que porcentagem significativa de municípios ainda não cumpre a exigência da legislação $n^{\circ}$ 11.947/2009. Assim sendo, o presente estudo visa analisar a dinâmica contemporânea do PNAE no estado gaúcho. A próxima seção dedica-se a apresentar os procedimentos metodológicos para avaliação da base de dados estatísticos disponíveis para os municípios do Rio Grande do Sul.

\section{METODOLOGIA}

Os procedimentos metodológicos envolveram a realização de pesquisa bibliográfica e o levantamento de dados estatísticos sobre a operacionalização do Programa Nacional de Alimentação Escolar no estado do Rio Grande do Sul (RS). Considerando a disponibilidade de dados sobre a temática de estudo, o recorte temporal de análise compreende o interstício de 2011 a 2016.

Foram selecionadas para análise as seguintes variáveis: i) os valores financeiros repassados pela União para os municípios do RS com a finalidade de operacionalizar o Programa Nacional de Alimentação Escolar; ii) os valores financeiros, procedentes da União, operacionalizados pelos municípios do RS, na compra de alimentos provenientes da agricultura familiar; iii) o índice de investimento municipal na compra de alimentos da agricultura familiar, derivado da razão entre os recursos repassados pela União para os municípios do RS e os valores negociados diretamente com a agricultura familiar.

Os dados analisados foram extraídos do Sistema de Gestão de Contas (SIGPC), disponibilizado pelo Fundo Nacional da Educação. Para transformar dados nominais em dados reais, os valores monetários foram deflacionados de acordo com o Índice de Preços ao Consumidor Amplo (IPCA) para o mês de fevereiro de 2018.

Instituiu-se uma análise de abordagem mista, pois as informações quantificáveis foram empregadas com a finalidade de compreender e classificar o objeto pesquisado, ao mesmo tempo em que o tratamento qualitativo procurou atribuir significado ao fenômeno 
pesquisado. Conforme Minayo (2001), as pesquisas qualitativas e quantitativas podem ser complementares, quando utilizadas de forma combinada, sem que haja uma dicotomia positivista ou compreensiva.

A Figura 1 apresenta as etapas desenvolvidas para a elaboração da presente pesquisa.
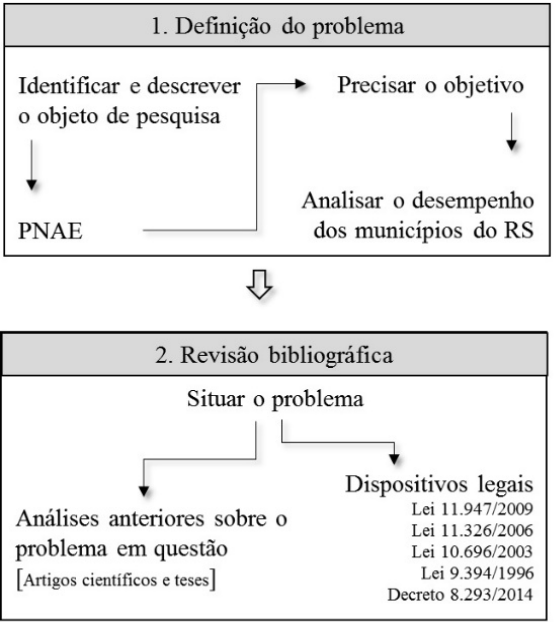

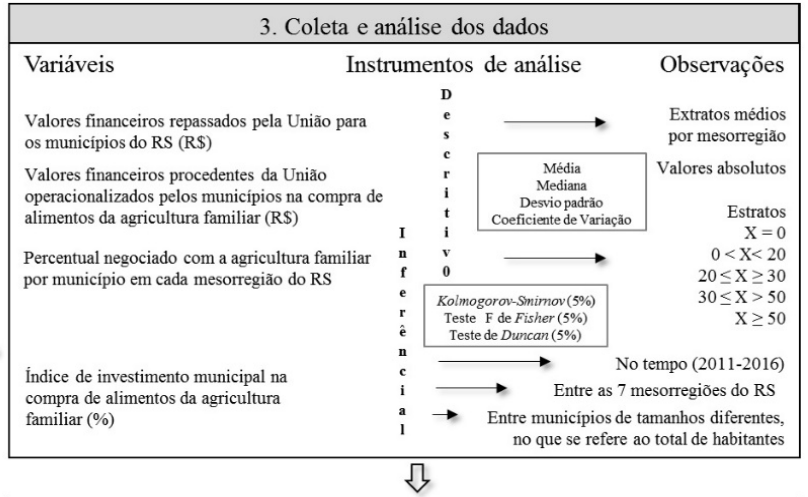

4. Apresentação dos resultados

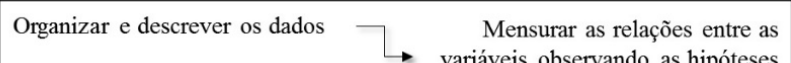
万

5. Considerações

Precisar o que se descobriu sobre o objeto de estudo

Apontar explicações para as informações obtidas

Figura 1. Etapas da elaboração da pesquisa

Os dados qualitativos foram utilizados essencialmente para apresentar o problema investigado neste estudo. Da mesma forma, foram utilizados para classificar o grau de integração de acesso aos mercados, para categorizar as modalidades de mercados acessadas pela agricultura familiar e para caracterizar as mesorregiões geográficas.

Além disso, o conjunto de técnicas descritivas foi utilizado para apresentar informações sobre a tendência central e a dispersão dos dados estatísticos disponíveis, com a operacionalização do teste de Kolmogorov-Smirnov (5\%). Em um primeiro momento, sintetizou-se a base de dados quantitativos a partir do emprego de instrumentos de estatística descritiva, a saber, a estimativa da média aritmética, mediana, desvio padrão, erro padrão e coeficiente de variação. Posteriormente, foram realizadas inferências estatísticas para análise de variância e comparação de médias. Para tanto, respectivamente, foram empregados os testes $\mathrm{F}$ de Fischer e de Duncan (ao nível de 5\% de significância).

Assim sendo, o estudo reúne três conjuntos de hipóteses:

i. $\mathrm{H}_{0}$ : Há diferença entre os percentuais médios de investimentos do PNAE na aquisição de alimentos da agricultura familiar entre os anos 2011, 2012, 2013, 2014, 2015 e 2016 no RS.

$\mathrm{H}_{1}$ : Não há diferença entre os percentuais médios de investimentos do PNAE na aquisição de alimentos da agricultura familiar entre os anos de 2011, 2012, 2013, 2014, 2015 e 2016 no RS.

ii. $H_{0}$ : Há diferença entre os percentuais médios de investimentos do PNAE na aquisição de alimentos da agricultura familiar nas mesorregiões Centro Ocidental, Centro Oriental, Região Metropolitana, Noroeste, Nordeste, Sudeste e Sudoeste do RS.

$\mathrm{H}_{1}$ : Não há diferença entre os percentuais médios de investimentos na aquisição de alimentos da agricultura familiar nas mesorregiões Centro Ocidental, Centro Oriental, Região Metropolitana, Noroeste, Nordeste, Sudeste e Sudoeste do RS.

iii. $\mathrm{H}_{0}$ : Há diferença entre os percentuais médios de investimentos do PNAE na aquisição de alimentos da agricultura familiar entre os municípios mais populosos e menos populosos do RS. 
$\mathrm{H}_{1}$ : Não há diferença entre os percentuais médios de investimentos do PNAE na aquisição de alimentos da agricultura familiar entre os municípios mais populosos e menos populosos do RS.

\section{A DINÂMICA DE ATUAÇÃO DOS MUNICÍPIOS DO RIO GRANDE DO SUL NO PROGRAMA NACIONAL DE ALIMENTAÇÃO ESCOLAR}

Os recursos financeiros destinados à compra de merenda escolar no Brasil apresentaram consideráveis incrementos nos últimos anos. Em 1995, foram investidos $\mathrm{R} \$$ 0,58 bilhões e em 2016 foram mais de $\mathrm{R} \$ 4$ bilhões (valores reais). Para o interstício de vinte anos, observou-se o crescimento de $75 \%$ no total de recursos destinados à merenda escolar. Ademais, houve crescimento de $25 \%$ do público atendido pela referida política pública, passando de 33,2 milhões de estudantes em 1995 para 41,5 milhões em 2015 (Fundo Nacional de Desenvolvimento da Educação, 2018).

Destaca-se que o coeficiente de distribuição dos recursos é ajustado mediante as variações nos valores arrecadados em fundo específico no Tesouro Nacional. A Lei $n^{\circ}$ 9.394/1996 estabelece que a União aplicará anualmente 18\% da receita resultante de impostos na manutenção e desenvolvimento do ensino público, enquanto os estados, o Distrito Federal e os municípios, 25\% (Brasil, 1996, art. 69). A partir do valor arrecadado é estipulado um índice por aluno/dia letivo de acordo com a modalidade de ensino catalogada no último censo escolar. Os índices obedecem aos seguintes critérios: creches: R\$1,07; pré-escola: $\mathrm{R} \$ 0,53$; escolas indígenas e quilombolas: $R \$ 0,64$; ensino fundamental e médio: $R \$ 0,36$; educação de jovens e adultos: $R \$ 0,32$; ensino integral: $R \$ 1,07$; Programa de Fomento às Escolas de Ensino Médio em Tempo Integral: $R \$ 2,00$; alunos que frequentam o Atendimento Educacional Especializado no contra turno: R\$ 0,53 (Fundo Nacional de Desenvolvimento da Educação, 2018).

O artigo quinto da Lei 11.947/2009 determina que os recursos financeiros consignados ao orçamento da União para execução do PNAE sejam repassados do Fundo Nacional de Desenvolvimento da Educação para os estados, Distrito Federal, municípios e às escolas federais. As secretarias estaduais da educação e as prefeituras municipais são as instâncias que operam os maiores volumes de recursos destinados ao programa de alimentação.

O estado do Rio Grande do Sul tem recebido aproximadamente 5\% dos recursos nacionais destinados à alimentação escolar (Tabela 2), de forma a beneficiar aproximadamente 2,4 milhões de estudantes. Em média, no intervalo dos seis anos, a União repassou $\mathrm{R} \$ 169.157 .228$ /ano para o estado. Deste total, cerca de $27,6 \%$ foi utilizada para aquisição de alimentos da agricultura familiar. Mesmo sem atingir o limite mínimo de 30\% estabelecido pela Lei 11.947/2009, essa é a maior média entre todos os estados brasileiros, superando os estados do Espírito Santo e Goiás que, até o ano de 2014, foram os estados que mais investiram recursos do PNAE na compra de alimentos da agricultura familiar - 26,7\% e 25,3\%, respectivamente (Fundo Nacional de Desenvolvimento da Educação, 2018).

Tabela 2. Indicadores do Programa Nacional da Alimentação Escolar associados à aquisição de gêneros alimentícios da agricultura familiar

\begin{tabular}{|c|c|c|c|c|c|c|}
\hline \multirow{2}{*}{$\begin{array}{l}\text { Indicadores do } \\
\text { PNAE }\end{array}$} & \multicolumn{6}{|c|}{ Anos } \\
\hline & 2011 & 2012 & 2013 & 2014 & 2015 & 2016 \\
\hline $\begin{array}{c}\text { Recursos } \\
\text { Transferidos } \\
\text { Brasil }(\mathrm{R} \$)\end{array}$ & 4.353 .465 .834 & 4.440 .576 .488 & 4.612.911.471 & 4.071 .623 .942 & 4.168.317.679 & 4.020 .728 .021 \\
\hline $\begin{array}{c}\text { Recursos } \\
\text { Transferidos Rio } \\
\text { Grande do Sul } \\
(R \$)\end{array}$ & 221.556 .149 & 227.757.246 & 235.199.548 & 199.742 .555 & 210.347.099 & 170.157 .855 \\
\hline
\end{tabular}


Tabela 2. Continuação...

\begin{tabular}{|c|c|c|c|c|c|c|}
\hline \multirow{2}{*}{$\begin{array}{l}\text { Indicadores do } \\
\text { PNAE }\end{array}$} & \multicolumn{6}{|c|}{ Anos } \\
\hline & 2011 & 2012 & 2013 & 2014 & 2015 & 2016 \\
\hline $\begin{array}{c}\text { Recursos } \\
\text { Transferidos } \\
\text { para os } \\
\text { municípios do } \\
\text { Rio Grande do } \\
\text { Sul (R\$) }\end{array}$ & 123.119.731 & 129.554 .350 & 138.242.594 & 123.006 .568 & 130.042 .269 & 118.500 .544 \\
\hline $\begin{array}{c}\text { Recursos } \\
\text { Investidos na } \\
\text { agricultura } \\
\text { familiar do Rio } \\
\text { Grande do Sul } \\
\text { (R\$) }\end{array}$ & 31.170 .666 & 39.967.873 & 63.356 .293 & 80.250 .067 & 67.214 .198 & 57.375 .144 \\
\hline$(\%)$ & 14,1 & 17,5 & 26,9 & 40,2 & 32,0 & 33,7 \\
\hline $\begin{array}{c}\text { Recursos } \\
\text { Investidos na } \\
\text { agricultura } \\
\text { familiar por meio } \\
\text { de compras } \\
\text { municipais no } \\
\text { Rio Grande do } \\
\text { Sul }(\mathrm{R} \$)\end{array}$ & 31.170 .666 & 39.967 .873 & 47.988 .854 & 56.744 .069 & 54.083 .164 & 45.564 .214 \\
\hline $\begin{array}{l}\text { Investido em } \\
\text { relação ao } \\
\text { transferido para } \\
\text { os municípios (\%) }\end{array}$ & 25,3 & 30,9 & 34,7 & 46,1 & 41,6 & 38,5 \\
\hline $\begin{array}{l}\text { Municípios que } \\
\text { receberam } \\
\text { recursos }\end{array}$ & 492 & 492 & 496 & 496 & 495 & 493 \\
\hline $\begin{array}{l}\text { Municípios que } \\
\text { não } \\
\text { apresentaram } \\
\text { compra da } \\
\text { agricultura } \\
\text { familiar }\end{array}$ & 91 & 47 & 53 & 37 & 20 & 26 \\
\hline $\begin{array}{l}\text { Percentual de } \\
\text { municípios* }\end{array}$ & 18,5 & 9,6 & 10,7 & 7,5 & 4,0 & 5,3 \\
\hline $\begin{array}{c}\text { Municípios que } \\
\text { cumpriram a Lei } \\
11.947\end{array}$ & 302 & 340 & 279 & 368 & 367 & 331 \\
\hline $\begin{array}{l}\text { Percentual de } \\
\text { municípios* }\end{array}$ & 61,4 & 69,1 & 56,3 & 74,2 & 74,1 & 67,0 \\
\hline
\end{tabular}

Nota: (*) A porcentagem é em relação aos municípios que receberam recurso e não ao total de municípios. Fonte: Dados do Fundo Nacional de Desenvolvimento da Educação (2018).

A parcela média de recursos repassados para o RS foi dividida entre a Secretaria Estadual da Educação (39,7\%) e as prefeituras municipais (60,3\%). De acordo com os dados estatísticos disponíveis, a secretaria estadual não realizou nenhuma negociação com a agricultura familiar antes de 2013, embora tenha recebido, nos seis anos analisados, $\mathrm{R} \$ 83.715 .733 /$ ano. Deste montante, transacionaram-se 13,6\% com a agricultura familiar. Já com relação à parcela de recursos repassados aos municípios ( $R \$$ 127.077.676/ano em média no período de análise), 36,7\% foram aplicados na compra de alimentos diretamente da agricultura familiar (Fundo Nacional de Desenvolvimento da Educação, 2018).

Sendo assim, a análise realizada é direcionada para descrever a execução financeira realizada pelos municípios, uma vez que receberam valor 1,5 vezes superior à Secretaria 
Estadual da Educação e aplicaram 4,1 vezes a mais recursos. Em síntese, os municípios representam mais de $80 \%$ de todos os recursos aplicados na compra de alimentos da agricultura familiar via PNAE no Rio Grande do Sul.

O Rio Grande do Sul é o estado brasileiro que tem o maior número de municípios que vêm cumprido com a meta estabelecida pela legislação, de forma que manteve média de 67\% no período analisado. Entre 2011 e 2016, a média percentual de municípios que não apresentaram compra da agricultura familiar foi de 10,7\% (Fundo Nacional de Desenvolvimento da Educação, 2018).

Vale mencionar que o Rio Grande do Sul é composto de 497 municípios e sua área total é de 281.730 mil km² (equivalente a 3,3\% da superfície brasileira). Possui população superior a onze milhões de habitantes (aproximadamente 5,4\% do Brasil), sendo o quinto estado mais populoso do Brasil (Instituto Brasileiro de Geografia e Estatística, 2017).

Conforme o Instituto Brasileiro de Geografia e Estatística (2017), o estado é subdividido em sete mesorregiões (Figura 2). Ao Norte, encontram-se as terras mais altas, colonizadas principalmente por imigrantes alemães e italianos no fim do século passado. Nesta porção está situada a Mesorregião Noroeste e parte das mesorregiões Centro Oriental e Nordeste. O modelo agrícola é diversificado, contudo aos poucos tem cedido espaço para lavouras mecanizadas e sistemas de produção mais especializados. A economia regional está baseada praticamente na produção de arroz, soja, milho, trigo e na agroindústria do tabaco (especialmente na Mesorregião Centro Oriental). Na pecuária, a criação de frangos, suínos e gado de leite tem relevada presença. Mais especificamente na Mesorregião Nordeste destacase a produção de fruticultura (vitivinicultura), além do estabelecimento de uma importante estrutura agroindustrial (de alimentos, bebidas, madeira e mobiliário) (Federação das Indústrias do Estado do Rio Grande do Sul, 2014).

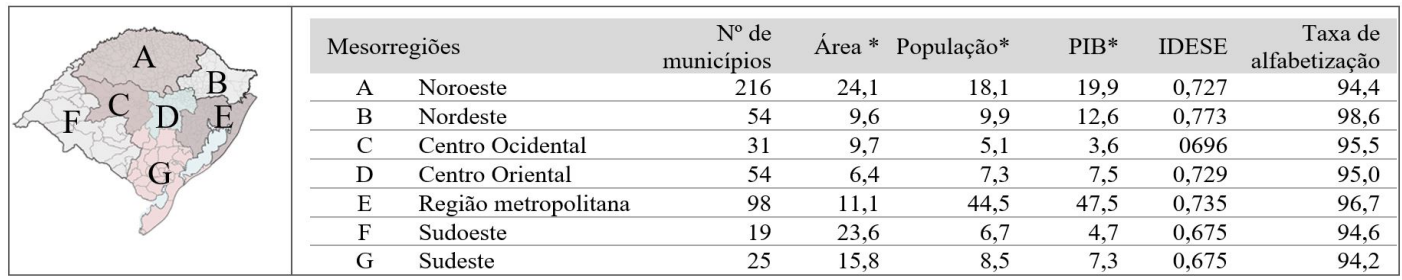

Figura 2. Características das mesorregiões estaduais do Rio Grande do Sul. Nota (*): Percentual em relação ao total do Estado. Fonte: Dados do Instituto Brasileiro de Geografia e Estatística (2017) e Federação das Indústrias do Estado do Rio Grande do Sul (2014).

O sul do estado, que inclui as mesorregiões Sudeste e Sudoeste, tem relevo levemente ondulado de média altitude. A ocupação é mais antiga e a economia é tradicionalmente baseada em pecuária extensiva, com forte presença do arroz e, mais recentemente, exploram-se a soja, o reflorestamento e a fruticultura. Próximo à cabeceira da Laguna dos Patos, estão as mesorregiões Metropolitana e parte da Mesorregião Nordeste. Esse território possui a maior concentração urbana, apresenta forte industrialização (petroquímica, metalmecânica, móveis e madeira, couro e calçados) e tem destaque no turismo. A pecuária, com a criação de suínos, equinos e frangos, também está presente (Federação das Indústrias do Estado do Rio Grande do Sul, 2014).

A Figura 3 ilustra como estão distribuídos proporcionalmente os 400 mil agricultores familiares no estado do Rio Grande do Sul (A), bem como a razão entre as médias dos recursos financeiros procedentes da União e os recursos investidos na compra de alimentos da agricultura familiar por município. Destaca-se que as cores mais escuras sugerem maior intensidade de agricultores familiares e de recursos do PNAE investidos. Em síntese, nota-se leve contraste nos recursos investidos nas mesorregiões Sudoeste e Sudeste, não obstante alguns dos municípios da Mesorregião Nordeste. 


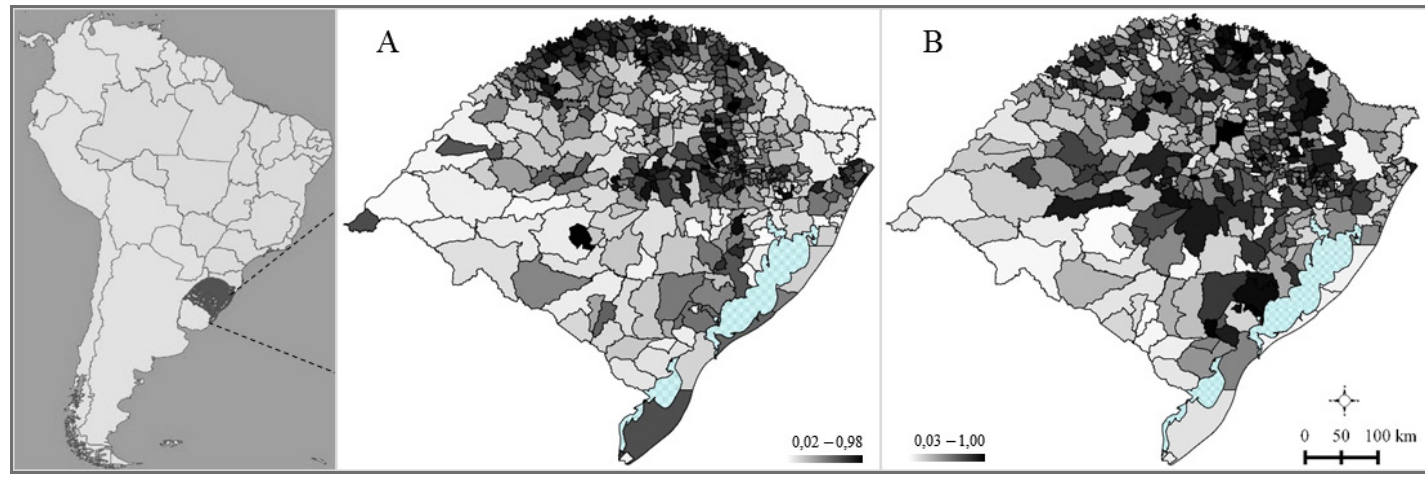

Figura 3. (A) Proporção entre o número de agricultores familiares e a população total nos municípios do RS; (B) Razão entre as médias dos recursos financeiros procedentes da União e os recursos investidos na compra de alimentos da agricultura familiar por município do RS no período de 2011 a 2016. Fonte: Dados estatísticos do Instituto Brasileiro de Geografia e Estatística $(2006,2013)$ e Fundo Nacional de Desenvolvimento da Educação (2018).

Com relação ao exame do percentual negociado com a agricultura familiar por município, entre as mesorregiões, a primeira estratificação foi efetuada a partir de cinco categorias: (i) municípios que não realizaram nenhuma compra de alimentos da agricultura familiar; (ii) municípios que transacionaram até $20 \%$ do recurso recebido com agricultores familiares; (iii) municípios que transacionaram acima de 20 a 30\% do recurso recebido com agricultores familiares; (iv) municípios que transacionaram acima de 30 a $50 \%$ do recurso recebido com agricultores familiares; e (v) municípios que transacionaram acima de $50 \%$ do recurso recebido com agricultores familiares. A Figura 4 compara o ordenamento entre as sete mesorregiões sul-rio-grandense. Inicialmente destaca-se que $67 \%$ dos municípios do estado atenderam a legislação brasileira e negociaram pelo menos $30 \%$ dos recursos destinados à compra de merenda escolar com a agricultura familiar.

Dentre as regiões do Rio Grande do Sul, o Centro Ocidental apresenta o maior número de municípios na condição legal e que negociaram com a agricultura familiar. Em 2014, mais de $90 \%$ dos municípios desta região cumpriram com a Lei 11.947/2009. Por outro lado, a Região Sudoeste do estado apresentou tímida participação no Programa Nacional de Alimentação Escolar. A referida região apresenta a menor participação entre os municípios que cumpriram o que determina a legislação (média de 33,8\% no período analisado) e um dos maiores índices de municípios que não adquiriram alimentos da agricultura familiar $(13,5 \%)$.

Sobre as demais regiões, alerta-se sobre o fato de que cerca de metade dos municípios do Sudeste não cumprirem a lei. Sobretudo, destaca-se a significativa participação dos municípios da região metropolitana (com predomínio de características urbanas) na compra de alimentos diretamente da agricultura.

Outro resultado importante revelado faz menção ao perfil dos municípios com maior percentual de recursos do PNAE comercializados com a agricultura familiar $(X \geq 50 \%)$. Para o período de 2011 a 2016, figuram dentre os municípios com melhor desempenho no PNAE sempre os mesmos 94 municípios. Desta forma, supõe-se que os municípios com melhor desempenho estão melhor consolidados na execução da Lei $n^{\circ} 11.947 / 2009$. A Mesorregião Centro Oriental destaca-se frente a este processo de consolidação, pois 17 dos 31 municípios estão na condição de ter destinado mais de $50 \%$ dos recursos do PNAE na compra de alimentos da agricultura familiar. 


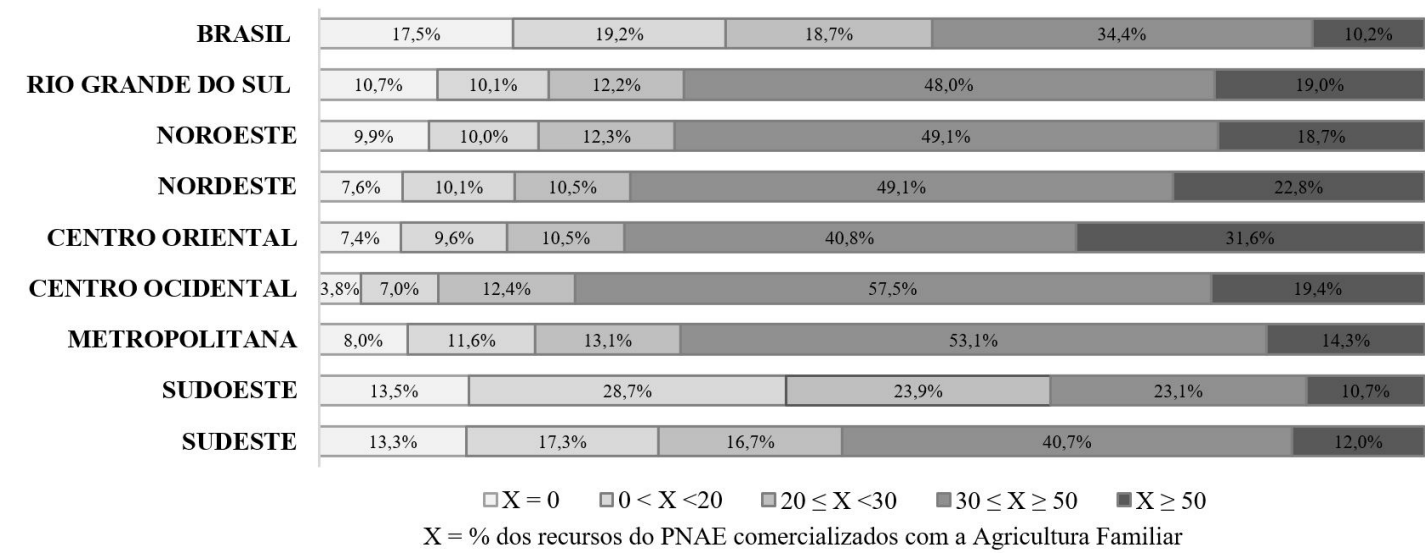

Figura 4. Frequência relativa dos municípios vis a vis aos diferentes percentuais de recursos do PNAE comercializados com a agricultura familiar no período de 2011 a 2016. Fonte: Dados do Fundo Nacional de Desenvolvimento da Educação (2018).

Em termos de recursos absolutos, a Mesorregião metropolitana recebeu o maior valor de recursos e investiu mais com compras da agricultura familiar ( $R \$ 44.097 .949$ e 14.669.782, respectivamente por ano entre 2011 e 2016). A Mesorregião Centro Ocidental recebeu menos recursos em valores absolutos ( $R \$ 4.835 .599 / a n o)$ e a Mesorregião Sudoeste investiu menos com compras da agricultura familiar ( $\mathrm{R} \$ 1.295 .729 / a n o)$.

Um dos objetivos desta análise é comparar o desempenho dos municípios de cada mesorregião na operacionalização dos recursos do PNAE. O índice resulta da simples razão estabelecida entre o total de recursos recebidos no ano e o total aplicado na agricultura familiar no mesmo período para cada município. Com isso, busca responder se existe diferença entre a média dos percentuais de recursos investidos na agricultura familiar entre as regiões e se estes índices se alteram no tempo.

Para avaliação e para comparar a distribuição dos dados entre os grupos, foi realizada a análise da variância, com a operação do teste $\mathrm{F}$ de Fisher. A Tabela 3 apresenta o resultado dos quadrados médio e dos coeficientes de variação para cada grupo analisado.

Tabela 3. Síntese da análise da variância do desempenho auferido pelos municípios das diferentes mesorregiões do RS na operacionalização do PNAE (2011 a 2016)

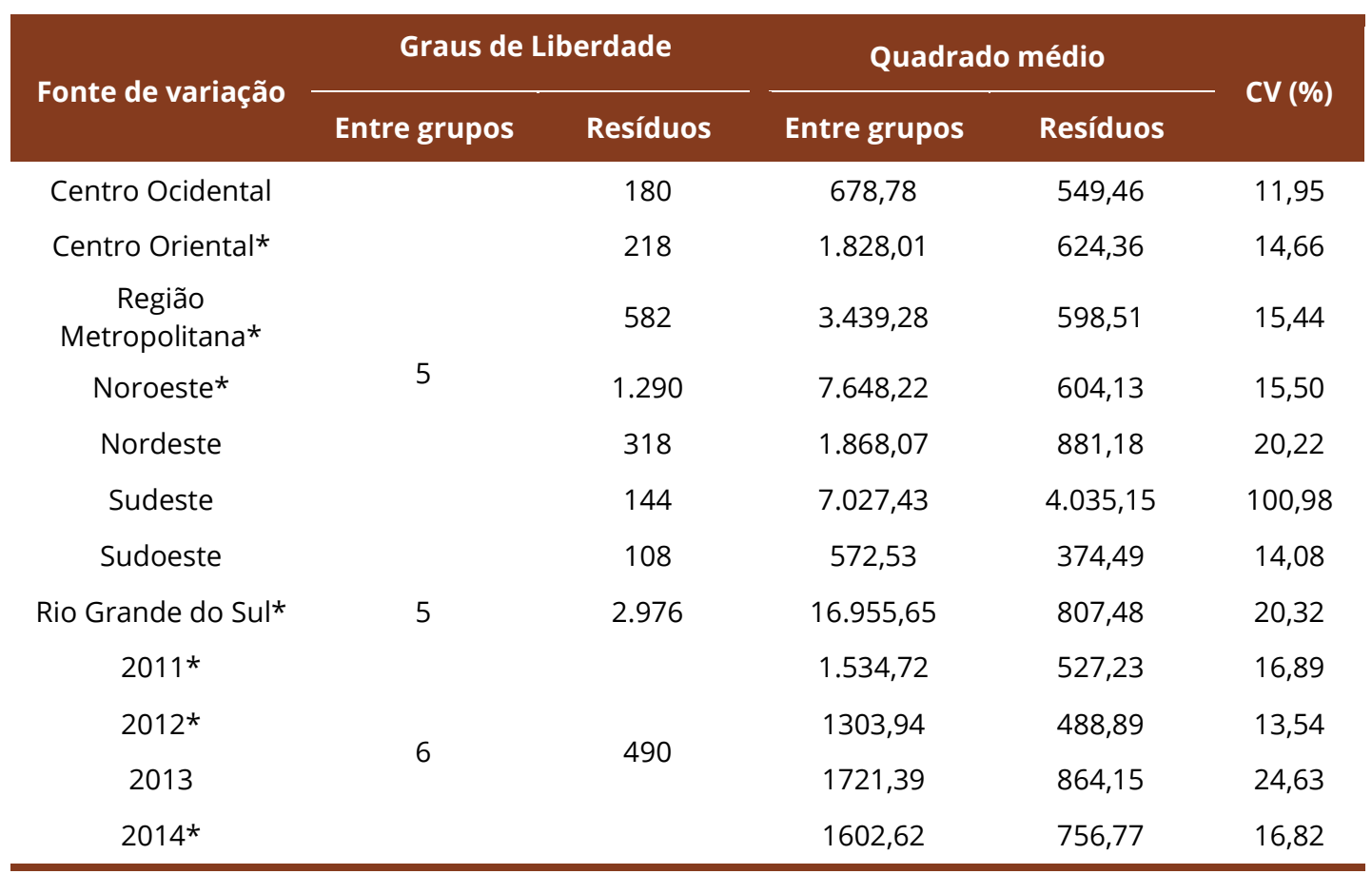


Tabela 3. Continuação...

\begin{tabular}{|c|c|c|c|c|c|}
\hline \multirow{2}{*}{ Fonte de variação } & \multicolumn{2}{|c|}{ Graus de Liberdade } & \multicolumn{2}{|c|}{ Quadrado médio } & \multirow{2}{*}{ CV (\%) } \\
\hline & Entre grupos & Resíduos & Entre grupos & Resíduos & \\
\hline $2015^{\star}$ & & & 4250,2 & 1538,35 & 31,75 \\
\hline $2016 *$ & & & 2290,2 & 573,27 & 14,87 \\
\hline
\end{tabular}

Nota: $\left(^{*}\right)$ Pelo menos um dos contrastes difere estatisticamente em nível de $5 \%$ de significância pelo teste $\mathrm{F}$. Fonte: Dados do Fundo Nacional de Desenvolvimento da Educação (2018).

Os percentuais médios de investimento na aquisição de produtos alimentícios da agricultura familiar via PNAE são mais elevados na Mesorregião Ocidental. Entretanto, não diferem estatisticamente, em nível de $5 \%$ de significância pelo teste de Duncan, dos percentuais das demais regiões, exceto para o percentual da Mesorregião Sudoeste (nos seis anos analisados) e da Mesorregião Sudeste (em apenas dois anos, 2011 e 2016). De maneira geral, a análise entre as regiões confirma inferioridade nos aportes dos recursos nas regiões situadas mais ao sul do estado, conforme apresentado na Tabela 4.

É difícil apontar para um único fator responsável por justificar as diferenças regionais de desempenho do PNAE na compra de alimentos da agricultura familiar, embora a avaliação de indicadores socioeconômicos possa sugerir associações ainda a serem exploradas pela literatura acadêmica. Assim como apontam Schabarum \& Triches (2019), infere-se sobre a expressão do relacionamento entre o percentual investido na compra de alimentos da agricultura familiar, a renda das regiões, a população em idade escolar e demais indicadores de cunho social e econômico.

Para fins de ilustração, estimou-se a correlação linear entre o Índice de Desenvolvimento Socioeconômico (IDESE) e os percentuais médios investidos na compra de alimento da agricultura familiar para as mesorregiões do RS no período 2011-2015. O coeficiente de Pearson indica que há um relacionamento linear do tipo moderado-alto entre as supracitadas variáveis (aproximadamente 0,66). Outrossim, seria oportuna a análise de variáveis referentes ao operacionalizar do PNAE, tais como apontam Mossmann et al. (2017). Para tal fim, demandar-se-ia a realização de pesquisa de campo para coleta de dados primários.

O estudo tem ainda como objetivo avaliar se os municípios elevaram a média percentual de participação da agricultura familiar no PNAE ao longo do tempo. Conforme dados dispostos na Tabela 4, entre 2011 e 2015 houve aumento consecutivo na média dos percentuais investidos na compra de produtos provenientes da agricultura familiar. Contudo, observa-se uma queda relativa da participação no ano de 2016.

Tabela 4. Média dos percentuais investidos na compra de alimentos da agricultura familiar entre 2011 e 2016 nas mesorregiões do Rio Grande do Sul

\begin{tabular}{|c|c|c|c|c|c|c|}
\hline \multirow{2}{*}{ Mesorregiões } & \multicolumn{6}{|c|}{ Médias } \\
\hline & 2011 & 2012 & 2013 & 2014 & 2015 & 2016 \\
\hline Centro Ocidental** & $40,73 \mathrm{~A}$ & $42,16 \mathrm{~A}$ & $43,49 \mathrm{~A}$ & $51,67 \mathrm{~A}$ & $51,32 \mathrm{~B}$ & $46,50 \mathrm{~A}$ \\
\hline Centro Oriental & $36,87 \mathrm{AB} b$ & $42,38 \mathrm{~A} a b$ & $39,44 \mathrm{~A} \mathrm{~b}$ & $52,28 \mathrm{~A} \mathrm{a}$ & $46,34 \mathrm{BC}$ ab & $38,27 \mathrm{AB} b^{*}$ \\
\hline Região Metropolitana* & $30,49 \mathrm{AB} C$ & $35,36 \mathrm{~A} \mathrm{bc}$ & $35,93 \mathrm{~A} \mathrm{bc}$ & $46,88 \mathrm{~A} \mathrm{a}$ & $42,63 \mathrm{BC} a b$ & $41,32 \mathrm{AB}$ ab \\
\hline Noroeste & $31,36 \mathrm{AB} C$ & $36,59 \mathrm{~A} \mathrm{~b}$ & $33,34 \mathrm{~A} \mathrm{bc}$ & $44,25 \mathrm{~A}$ a * & $44,42 \mathrm{BC}$ a & $43,89 \mathrm{~A} \mathrm{a}$ \\
\hline Nordeste & $35,26 \mathrm{AB} b$ & $40,09 \mathrm{~A} a b$ & $40,55 \mathrm{~A} a b$ & $48,26 \mathrm{~A} \mathrm{a}$ & $50,77 \mathrm{~B}$ a & $46,54 \mathrm{~A} a b$ \\
\hline Sudeste & $25,85 \mathrm{BC} b$ & $34,52 \mathrm{~A} \mathrm{~b}$ & $33,55 \mathrm{~A} \mathrm{~b}$ & $41,86 \mathrm{~A}$ ab & $72,51 \mathrm{~A} a^{*}$ & $31,46 \mathrm{BC} b$ \\
\hline Sudoeste** & $17,98 \mathrm{C}$ * & $21,67 \mathrm{~B}$ & $19,24 \mathrm{~B}$ & 29,68 B & $31,12 \mathrm{C}$ & $21,89 \mathrm{~B}$ \\
\hline Rio Grande do Sul* & $32,01 \mathrm{~d}$ & $36,11 \mathrm{c}$ & $35,40 \mathrm{~cd}$ & 45,86 a & 46,30 a & $38,55 \mathrm{~b}$ \\
\hline
\end{tabular}

Notas: Médias seguidas pela mesma letra maiúscula na coluna e as médias seguidas pela mesma letra minúscula na linha não diferem estatisticamente pelo teste de Duncan (5\%). (*) A distribuição da amostra é significativamente diferente da distribuição normal pelo teste de Kolmogorov-Smirnov em nível de $5 \%$ de significância. (**) Os contrastes NÃO diferem estatisticamente em nível de 5\% pelo teste de F. Fonte: Dados do Fundo Nacional de Desenvolvimento da Educação (2018). 
A despeito do crescimento dos valores investidos nos anos iniciais da série analisada, o decrescimento de investimentos no ano mais contemporâneo suscita dúvidas quanto ao processo de consolidação deste mercado institucional e, por conseguinte, da capacidade de inserção de agricultores familiares neste canal de comercialização. De fato, a instabilidade política e econômica do ano de 2016 pode ter gerado externalidades negativas sobre a expansão do PNAE nas diferentes regiões do estado.

Finalmente, foi analisado se há diferença entre a otimização dos recursos com a agricultura familiar entre os municípios mais e menos populosos do estado gaúcho. Para tanto, considerou-se a população total dos municípios. O número total de habitantes é uma variável proxy que, por um lado, sinaliza o potencial escolar e, portanto, pode indicar incrementos na demanda de alimentos e, por outro lado, denota dificuldades em termos de operacionalização, uma vez que as entregas devem ser feitas ponto a ponto. Por conseguinte, cabe aos fornecedores (grupo de agricultores familiares) adotar medidas que garantam o transporte dos alimentos. Cabe mencionar que as dificuldades na constituição da rede de relacionamentos em nível local - entre as secretarias estaduais, as prefeituras municipais, as escolas e os agricultores familiares - tendem a aparecer como umas das limitantes do processo de consolidação do PNAE (Mossmann et al., 2017; Schabarum \& Triches, 2019).

Tendo em vista o exposto, avaliou-se o desempenho dos municípios no PNAE vis-à-vis ao número total de habitantes, considerando três critérios de eficiência: i) suposta demanda superior nos municípios mais populosos; ii) estratégias operacionais do programa; e iii) relacionamento entre os órgãos executores e os agricultores familiares. Assim, a avaliação foi realizada com base em dados secundários disponíveis para três grupos de municípios: i) municípios com 10 mil habitantes ou menos, que totalizam amostra de 331 municípios; ii) municípios com mais de 10 e menos de 100 mil habitantes, que totalizam amostra de 146 municípios; e iii) municípios com mais de 100 mil habitantes, que compreendem amostra de 20 municípios no RS. Adicionalmente, comparou-se a proporção de agricultores familiares em relação ao total de habitantes para os três grupos de municípios supracitados.

Os elementos descritivos da Tabela 5 comparam a porcentagem de investimentos na agricultura familiar e a proporção de agricultores familiares em relação ao total de agricultores para os três grupos de municípios. Embora o índice médio de investimento de recursos do PNAE na agricultura familiar seja maior e mais uniforme nos grupos de municípios com menos de 100 mil habitantes, o contraste entre as médias não difere estatisticamente do desempenho do grupo de municípios com mais de 100 mil (em nível de $5 \%$ de significância pelo teste $F$ ).

Tabela 5. Análise descritiva da média dos investimentos na compra de alimentos da agricultura familiar e a distribuição de agricultores familiares entre maiores e menores municípios do RS

\begin{tabular}{|c|c|c|c|c|c|c|}
\hline \multirow{3}{*}{ Indicadores } & \multicolumn{6}{|c|}{ População (mil habitantes) } \\
\hline & \multicolumn{2}{|c|}{ Menos de 10} & \multicolumn{2}{|c|}{ Entre 10 e 100} & \multicolumn{2}{|c|}{ Mais 100} \\
\hline & $\begin{array}{l}\text { Invest. } \\
\text { na AF }\end{array}$ & AF & $\begin{array}{l}\text { Invest. } \\
\text { na AF* }\end{array}$ & AF & $\begin{array}{c}\text { Invest. na } \\
\text { AF* }\end{array}$ & AF* \\
\hline Média & 39,71 & 86,29 & 38,99 & 79,21 & 36,32 & 73,74 \\
\hline Mediana & 38,91 & 89,70 & 37,92 & 84,90 & 32,39 & 75,45 \\
\hline Desvio padrão & 15,97 & 12,23 & 16,10 & 16,69 & 20,24 & 16,00 \\
\hline Erro padrão & 0,87 & 0,67 & 1,33 & 1,38 & 4,52 & 3,57 \\
\hline $\begin{array}{c}\text { Coeficiente de } \\
\text { variação (\%) }\end{array}$ & 40,20 & 14,18 & 41,29 & 21,08 & 55,73 & 21,70 \\
\hline
\end{tabular}

(*) A distribuição NÃO é significativamente diferente da distribuição normal pelo teste de kolmogorov-Smirnov em nível de 5\% de significância. Fonte: Dados do Instituto Brasileiro de Geografia e Estatística (2006) e Fundo Nacional de Desenvolvimento da Educação (2018).

Logo, através da análise dos dados disponíveis no Fundo Nacional do Desenvolvimento da Educação, o estudo conclui que: 
i. O comportamento das compras de alimentos da agricultura familiar difere entre as mesorregiões do Rio Grande de Sul, sendo que a Mesorregião Centro Ocidental apresentou o maior índice de operacionalização, seguida pelas mesorregiões Nordeste, Centro Oriental, Sudeste e Noroeste, diferenciando-se estatisticamente da Mesorregião Sudoeste. Portanto, rejeita-se a hipótese nula para o índice médio de investimentos do PNAE na aquisição de alimentos da agricultura familiar entre as sete mesorregiões do Rio Grande do Sul.

ii. Houve evolução do índice de investimento no período no estado do Rio Grande do Sul, sendo que a maior média foi observada no ano de 2015 (penúltimo ano analisado da série estatística disponível). Desta forma, rejeita-se a hipótese nula para o índice médio de investimentos do PNAE na aquisição de alimentos da agricultura familiar no período de 2011 a 2016.

iii. Há maior variação dos índices médios de investimentos na compra de produtos da agricultura familiar nos municípios mais populosos no estado do Rio Grande do Sul (em comparação aos municípios menos populosos). Entretanto, não se rejeita a hipótese nula para o índice médio de investimentos do PNAE na aquisição de alimentos da agricultura familiar entre os municípios mais e menos populosos. Por conseguinte, não é possível afirmar que o tamanho do município, em termos populacionais, exerce influência sobre o desempenho na aquisição de produtos da agricultura familiar, por meio dos recursos do PNAE.

\section{CONSIDERAÇÕES FINAIS}

No tocante à operacionalização do Programa Nacional de Alimentação Escolar, o Rio Grande do Sul possui posição de destaque entre os demais estados brasileiros, uma vez que transacionou 24,9\% dos recursos disponibilizados com a agricultura familiar (2011- 2016). Enquanto a porcentagem média de investimento na agricultura familiar do Brasil atingiu aproximadamente $15 \%$ do total dos recursos no mesmo período, $67 \%$ dos municípios sul rio-grandenses cumpriram com a meta estabelecida pela legislação, a citar, o artigo $5^{\circ}$ da Lei 11.947/2009, que prevê que 30\% dos recursos do PNAE devem ser transacionados com a agricultura familiar (Fundo Nacional de Desenvolvimento da Educação, 2018).

Em síntese, a relação entre o recurso recebido da União e investido na agricultura familiar por parte dos municípios do Rio Grande do Sul, via Programa Nacional de Alimentação Escolar, tem demonstrado uma tendência crescente no tempo, tanto na quantidade de municípios aderindo ao programa como no volume de recursos negociados com agricultura familiar. Contudo, ainda são necessários avanços para que haja o cumprimento da legislação e a efetiva promoção do bem-estar social.

Sobretudo, a queda dos recursos destinados ao PNAE e da participação relativa da agricultura familiar neste mercado institucional no ano de 2016 põe em xeque o processo de expansão e amadurecimento dos instrumentos de política pública conquistados em anos anteriores. Destarte, a mobilização social, a articulação entre produtores rurais e entidades governamentais, além da promoção de canais de informação mais eficientes podem ser alternativas para que os municípios gaúchos sejam mais efetivos no acesso ao Programa Nacional de Alimentação Escolar. O papel das lideranças locais, através da socialização das informações e da construção de conhecimentos é fundamental para que os agricultores familiares tenham acesso às oportunidades realizadas pela referida política pública.

Diante da opção governamental em apoiar a agricultura familiar e por entender que a criação dos mercados institucionais apresenta vantagens para a sociedade, diagnosticar o desempenho do Programa Nacional de Alimentação Escolar nos municípios gaúchos é um compromisso que deve ser assumido pelas entidades envolvidas e pela comunidade acadêmica. Ainda, considerando que a Região Sul do Brasil e o estado do Rio Grande do Sul apresentam, proporcionalmente, o maior número de municípios que cumpriram a legislação e tem os melhores índices de investimentos de recursos na agricultura familiar, comparados com outras regiões e estados, infere-se que os desafios para operacionalização da política pública podem ser minimizados ao passo que as trajetórias de aprendizado evoluam. 
Neste sentido, salienta-se a importância da avaliação de dados estatísticos para monitoramento das ações do Programa Nacional de Alimentação Escolar, sendo pertinentes também análises qualitativas que indiquem os pontos positivos e negativos da operacionalização dos investimentos desta política pública. Estudos localizados podem indicar as deficiências apresentadas pelos gestores dos municípios na execução da legislação vigente e as potencialidades de expansão das ações do programa em nível local e regional.

\section{REFERÊNCIAS}

Abramovay, R. (1992). Paradigmas do capitalismo agrário em questão. São Paulo-Rio de JaneiroCampinas: Editora Hucitec, ANPOCS, Editora da Unicamp.

Aquino, J. R., Gazolla, M., \& Schneider, S. (2018). Dualismo no campo e desigualdades internas na agricultura familiar brasileira. Revista de Economia e Sociologia Rural, 56(1), 123-142.

Becker, C., \& Sacco dos Anjos, F. (2015). São os mercados institucionais da agricultura familiar um instrumento para o desenvolvimento rural? Estudo de caso em municípios do sul do Brasil. Revista de la Facultad de Agronomía, 114(1), 143-152.

Brasil. (1996, Dezembro 23). Lei ${ }^{\circ}$ 9.394, de 20 de dezembro de 1996. Estabelece as diretrizes e bases da educação nacional. Diário Oficial [da] República Federativa do Brasil, Brasília.

Brasil. (2003, Julho 3). Lei no 10.696, de 2 de julho de 2003. Dispõe sobre a repactuação e o alongamento de dívidas oriundas de operações de crédito rural, e dá outras providências. Diário Oficial [da] República Federativa do Brasil, Brasília.

Brasil. (2006, Julho 25). Lei no 11.326, de 24 de julho de 2006. Estabelece as diretrizes para a formulação da Política Nacional da Agricultura Familiar e Empreendimentos Familiares Rurais. Diário Oficial [da] República Federativa do Brasil, Brasília.

Brasil. (2009, Junho 17). Lei n 11.947, de 16 de junho de 2009. Dispõe sobre o atendimento da alimentação escolar e do Programa Dinheiro Direto na Escola aos alunos da educação básica; altera as Leis nos 10.880, de 9 de junho de 2004, 11.273, de 6 de fevereiro de 2006, 11.507, de 20 de julho de 2007; revoga dispositivos da Medida Provisória no 2.178-36, de 24 de agosto de 2001, e a Lei no 8.913, de 12 de julho de 1994; e dá outras providências. Diário Oficial [da] República Federativa do Brasil, Brasília.

Brasil. Ministério do Desenvolvimento Social - MDS. (2016). Aquisição de produtos da agricultura familiar para a alimentação escolar. $2^{a}$ edição - versão atualizada com a Resolução CD/FNDE $n^{\circ}$ 04/2015. Brasília.

Brasil. Ministério do Desenvolvimento Agrário - MDA. (2017a). Programas: PAA. Brasília. Recuperado em 28 de abril de 2017, de http://www.mda.gov.br/sitemda/secretaria/saf-paa/sobre-o-programa

Brasil. Ministério do Desenvolvimento Social e Agrário. (2017b). Plano Nacional de Segurança Alimentar e Nutricional - PLANSAN 2016-2019. Brasília: Câmara Interministerial de Segurança Alimentar e Nutricional. Recuperado em 27 de maio de 2019, de https://www.mds.gov.br/webarquivos/arquivo/seguranca_alimentar/caisan/plansan_2016_19.pdf

Bromley, D. W. (1997). Rethinking markets. American Journal of Agricultural Economics, 79(5), 1383-1393.

Delgado, G. C., \& Bergamasco, S. M. P. P. (Eds.). (2017). Agricultura familiar brasileira: desafios e perspectivas de futuro. Brasília: Ministério do Desenvolvimento Agrário.

Federação das Indústrias do Estado do Rio Grande do Sul - FIERGS. Unidade de Estudos Econômicos. (2014). Panorama econômico do Rio Grande do Sul. Recuperado em 8 de janeiro de 2018, de http://www.fiergs.org.br/sites/default/files/Panorama_Econ\%C3\%B4mico_2014.pdf

Ferigollo, D., Kirsten, V. R., Heckler, D., Figueredo, O. A. T., Perez-Cassarino, J., \& Triches, R. M. (2017). Aquisição de produtos da agricultura familiar para alimentação escolar em municípios do Rio Grande do Sul. Revista de Saude Publica, 51(6), 1-10.

Fundo Nacional de Desenvolvimento da Educação - FNDE. Ministério da Educação. (2014). Aquisição de produtos da agricultura familiar para a alimentação escolar: manual. Brasília. Recuperado em 8 de setembro de 2017, de www.fnde.gov.br/centrais-de-conteudos/publicacoes/category/116alimentacao-escolar?download=9870:pnae-informe-2016-03-manual-pnae-2-edicao

Fundo Nacional de Desenvolvimento da Educação - FNDE. (2018). Dados da agricultura familiar. Brasília. Recuperado em 5 de fevereiro de 2018, de http://www.fnde.gov.br/programas/pnae/pnaeconsultas/pnae-dados-da-agricultura-familiar 
Gazolla, M., \& Schneider, S. (2013). Qual "fortalecimento" da agricultura familiar? Uma análise do Pronaf crédito de investimento e investimento no Rio Grande do Sul. Revista de Economia e Sociologia Rural, 51(1), 45-68.

Instituto Brasileiro de Geografia e Estatística - IBGE. (2006). Censo Agropecuário 2006. Rio de Janeiro. Recuperado em 27 de agosto de 2017, de http://www.sidra.ibge.gov.br/bda/pesquisas/ca/default.asp?o=2\&i=P\#12

Instituto Brasileiro de Geografia e Estatística - IBGE. (2013). Geociências. Brasília. Recuperado em 4 de outubro de 2019, de https://www.ibge.gov.br/pt/inicio.html

Instituto Brasileiro de Geografia e Estatística - IBGE. (2017). Estimativa da população 2017. Rio de Janeiro. Recuperado em 12 de janeiro de 2018, de http://cod.ibge.gov.br/2VWFB

Maciel, L. R. (2008). Mercado institucional de alimentos: potencialidades e limites para a agricultura familiar (Dissertação de mestrado). Faculdade de Agronomia e Medicina Veterinária da Universidade de Brasília, Brasília.

Minayo, M. C. S. (Ed.). (2001). Pesquisa social: teoria, método e criatividade (18. ed.). Petrópolis: Vozes.

Mossmann, M. P., Teo, C. R. P. A., Busato, M. A., \& Triches, R. M. (2017). Interface between family farming and school feeding: barriers and coping mechanisms from the perspective of different social actors in Southern Brazil. Revista de Economia e Sociologia Rural, 55(2), 325-342.

Ploeg, J. D. V. D. (2008). Camponeses e impérios alimentares: lutas por autonomia e sustentabilidade na era da globalização. Porto Alegre: UFRGS.

Polanyi, K. (1980). A grande transformação: as origens da nossa época (3. ed.). Rio de Janeiro: Campus.

Rockett, F. C., Corrêa, R. S., Pires, G. C., Machado, L. S., Hoerlle, F. S., Souza, C. P. M., \& Oliveira, A. B. A. (2019). Family farming and school meals in Rio Grande do Sul, Brazil. Ciência Rural, 49(2).

Rozendo, C., Bastos, F. B. C., \& Molina, W. S. L. (2013). Desafios institucionais para a inclusão da agricultura familiar no Programa Nacional de Alimentação Escolar. Revista Cronos, 14(2), 23-35.

Sabourin, E. M. M. (2011). Teoria da reciprocidade e sócio-antropologia do desenvolvimento. Sociologias, 27, 24-51.

Sabourin, E., Xavier, J. H. V., \& Triomphe, B. (2009). Um olhar sobre os enfoques e métodos no Projeto Unaí. In M. N. Oliveira, J. H. V. Xavier \& S. C. R. Almeida (Eds.), Projeto Unaí: pesquisa e desenvolvimento em assentamentos de reforma agrária (pp. 53-93). Planaltina: Embrapa Cerrados.

Schabarum, J. C., \& Triches, R. M. (2019). Aquisição de produtos da agricultura familiar em municípios paranaenses: análise dos produtos comercializados e dos preços praticados. Revista de Economia e Sociologia Rural, 57(1), 49-62.

Schneider, S. (2016). Mercados e agricultura familiar. In F. C. Marques, M. A. Conterato \& S. Schneider (Eds.), Construção de mercados e agricultura familiar: desafios para o desenvolvimento rural (1. ed., Cap. 4, pp. 93-140). Porto Alegre: UFRGS.

Schneider, S., \& Escher, F. (2011). A contribuição de Karl Polanyi para a sociologia do desenvolvimento rural. Sociologias, 13(27), 180-220.

Triches, R. M., \& Schneider, S. (2010). Alimentação escolar e agricultura familiar: reconectando o consumo à produção. Saúde e Sociedade, 19(4), 933-945.

Troian, A., \& Caldas, N. V. (2018). O Programa Nacional de Alimentação Escolar: uma análise de desempenho na execução dos recursos com a agricultura familiar. Revista Brasileira de Gestão e Desenvolvimento Regional, 14(3), 219-242.

Veiga, J. E. (1991). O desenvolvimento agrícola: uma visão histórica. São Paulo: Edusp.

Veiga, J. E. (1992). Uma linha estratégica de desenvolvimento agrícola. Revista de Economia Política, 12(2).

Wanderley, M. N. B. (2003). Agricultura familiar e campesinato: rupturas e continuidade. Estudos Sociedade e Agricultura, 21(10), 42-61.

Wilkinson, J. (2008). Mercados, redes e valores: o novo mundo da agricultura familiar. Porto Alegre: UFRGS.

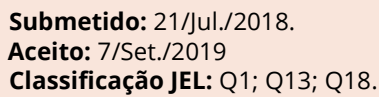

